\title{
Etiologic Framework for the Study of Neurodegenerative Disorders as Well as Vascular and Metabolic Comorbidities on the Grounds of Shared Epidemiologic and Biologic Features
}

\author{
Jesús de Pedro-Cuesta ${ }^{1,2 *}$, Pablo Martínez-Martín ${ }^{1,2}$, Alberto Rábano ${ }^{3}$, \\ María Ruiz-Tovar ${ }^{1,2}$, Enrique Alcalde-Cabero ${ }^{1,2}$ and Miguel Calero ${ }^{2,3,4}$ \\ ${ }^{1}$ Department of Applied Epidemiology, National Center for Epidemiology, Carlos III Institute of Health, Madrid, Spain, \\ ${ }^{2}$ Consortium for Biomedical Research in Neurodegenerative Diseases (CIBERNED), National Institute of Health Carlos III, \\ Madrid, Spain, ${ }^{3}$ Alzheimer Disease Research Unit, CIEN Foundation, Queen Sofia Foundation Alzheimer Center, Madrid, \\ Spain, ${ }^{4}$ Chronic Disease Programme, Carlos III Institute of Health, Majadahonda, Madrid, Spain
}

OPEN ACCESS

Edited by:

Myra Elizabeth Conway, The University of the West of

England, UK

Reviewed by: Kiyoka Kinugawa, Hôpital Charles Foix, France Arubala Reddy, Texas Tech University Health

Sciences Center, USA

${ }^{*}$ Correspondence: Jesús de Pedro-Cuesta jpedro@isciii.es

Received: 28 January 2016 Accepted: 27 May 2016

Published: 13 June 2016

Citation:

de Pedro-Cuesta J, Martínez-Martín P, Rábano A, Ruiz-Tovar M, Alcalde-Cabero E and Calero M (2016) Etiologic Framework for the Study of Neurodegenerative Disorders as Well as Vascular and Metabolic Comorbidities on the Grounds of Shared Epidemiologic and Biologic Features.

Front. Aging Neurosci. 8:138. doi: 10.3389/fnagi.2016.00138
Background: During the last two decades, protein aggregation at all organismal levels, from viruses to humans, has emerged from a neglected area of protein science to become a central issue in biology and biomedicine. This article constitutes a risk-based review aimed at supporting an etiologic scenario of selected, sporadic, protein-associated, i.e., conformational, neurodegenerative disorders (NDDs), and their vascular- and metabolic-associated ailments.

Methods: A rationale is adopted, to incorporate selected clinical data and results from animal-model research, complementing epidemiologic evidences reported in two prior articles.

Findings: Theory is formulated assuming an underlying conformational transmission mechanism, mediated either by horizontal transfer of mammalian genes coding for specific aggregation-prone proteins, or by xeno-templating between bacterial and host proteins. We build a few population-based and experimentally-testable hypotheses focusing on: (1) non-disposable surgical instruments for sporadic Creutzfeldt-Jakob disease (sCJD) and other rapid progressive neurodegenerative dementia (sRPNDd), multiple system atrophy (MSA), and motor neuron disease (MND); and (2) specific bacterial infections such as $B$. pertussis and $E$. coli for all forms, but particularly for latelife sporadic conformational, NDDs, type 2 diabetes mellitus (T2DM), and atherosclerosis where natural protein fibrils present in such organisms as a result of adaptation to the human host induce prion-like mechanisms.

Conclusion: Implications for cohort alignment and experimental animal research are discussed and research lines proposed.

Keywords: epidemiological patterns, etiology of conformational protein deposits, templating underlying risk/progression, disease induction vs. transmission in amyloid, multidisciplinary research overlaps 


\section{INTRODUCTION}

During the last two decades, protein aggregation at all organismal levels, from viruses to humans, has emerged from a neglected area of protein science to become a central issue in biology and biomedicine (Villar-Piqué and Ventura, 2012) The expanding knowledge in the field has particularly benefited our understanding of neurodegenerative disorders (NDDs). At the present time, it is widely acknowledged that templating (the basic mechanism generating protein misfolding, aggregation, deposit, and cell-to-cell transfer of certain pathogenic proteins) would be able to explain many features of the subclinical course and clinical manifestations of NDDs (Warren et al., 2013). Transcellular disease propagation of the pathogenic protein along existing anatomic structures (neural networks) would also explain the progression from the varied clinical patterns of NDDs (denoted as phenotypic heterogeneity) to a phenotypically converging, similar status, where a wide loss of cognitive, motor and sensory functions occur (Warren et al., 2013).

In a prior article, we selected 11 neurodegenerative conditions defined by clinical, neuropathological and biochemical features expressing different sets of single or combined misfolded protein deposits, and described lifecourse-related epidemiologic features (age-specific incidences and disease risk factors or disease progression predictors), thereby allowing for a meaningful, framed and unifying view of each disorder and its post-mortem biochemical signature (de Pedro-Cuesta et al., 2015). At a second step, we used a modified definition of the driver concept proposed by Sutherland to identify risk factors of specific proteins affecting different NDDs (Sutherland et al., 2011) and, having in mind the common amyloid nature of the pathogenic proteins involved, we identified selected traits of the epidemiology of sporadic, protein-associated, i.e., conformational, NDDs (sCNDD) useful for interpreting epidemiologic findings and relationships of the entities listed in Table 1 (Gunnarsson et al., 1996; Marmorstein et al., 2002; Peng et al., 2005; Irwin et al., 2013; Prusiner et al., 2015; de Pedro-Cuesta et al., 2016). In this third article we face a cumulative etiologic approach taking into account recent experimental data on transmissibility of multiple system atrophy (MSA; Prusiner et al., 2015).

Accordingly, the purpose of this work was: (a) to complement and anchor the interpretation of each driver with selected results of clinical or animal-model research; (b) to propose etiologic theory pointing to basic mechanisms and specific causal hypotheses testable by study designs, for epidemiologic or experimental research; and (c) in line with recent initiatives, to propose public health developments.

\section{SEARCH STRATEGY AND SELECTION CRITERIA}

References for this review were identified by searches used in prior articles (de Pedro-Cuesta et al., 2015, 2016), by diverse searches of MEDLINE with limits from 1995 to September
2015, relevant for entities on study, and reference lists from relevant articles. Reports in MEDLINE in all languages, using each of the following diagnostic search terms combined with etiology, i.e., dementia, Creutzfeldt-Jakob syndrome, motor neurone disease (MND), amyotrophic lateral sclerosis (ALS), fronto-temporal dementia (FTD), MSA, Parkinson's disease (PD), Lewy body disease (LBD), Alzheimer's disease (AD), rapid progressive dementia, age-related macular degeneration (AMD) and Huntington's disease (HD). There were no language restrictions. Driver specific reference lists were built. The final reference list consisted of a compendium of an approximately twice the size of full-text consultation work. As a literature review based proposal, the study does not require ethical assessment.

\section{DATA SUPPORTING AMYLOID-RELATED ETIOLOGY ACCORDING TO SPECIFIC DRIVERS AND SUCCINCT THEORY}

\section{Driver 1. Low Age-at-Exposure Related Susceptibility to Environmental Exposure Effects}

Driver 1 builds on the following specific epidemiologic observations: (a) age at first major whooping cough epidemic and PD incidence in Iceland; (b) bovine spongiform encephalopathy and variant Creutzfeldt-Jakob disease (vCJD); (c) age at first human growth hormone $(\mathrm{hGH})$ treatment and accidentally transmitted CJD (atCJD) in the UK; and (d) risk of sporadic Creutzfeldt-Jakob disease (sCJD) from routine surgery followed by a $\geq 20$-year latency period in Denmark and Sweden.

When fitted to a linear model, risk of PD increased with age at first whooping cough epidemic, a proxy of median age at BP infection (de Pedro-Cuesta et al., 1996). The susceptibility function for vCJD followed an inverted $\mathrm{V}$ shaped profile peaking at approximately 10 years. For sCJD, we observed that surgery at juvenile age ( $<30$ years) yielded the highest risk (OR 12.80; 95\% CI 2.56-64.0). Associations between developmental factors and risk of AD (Savica et al., 2013) and PD (Barlow et al., 2007) might support driver 1 validity for late-life sCNDD (for a review see de Pedro-Cuesta et al., 2016).

\section{Complementary Findings}

- Neuropathologically proven AD associated with atCJD has been reported in a young patient who received a dura mater graft (Preusser et al., 2006).

- A significantly high incidence of MND (based on three cases) has recently been described in a young cohort of hGH recipients in the USA (Irwin et al., 2013).

- Potential host-to-cell induction of $\alpha$-synuclein degeneration from patients diagnosed with $\mathrm{PD}$ who received fetal/embryonic tissue grafts, and disease induction by seeding in the $\alpha$-synuclein and tau mouse models, supported the inference of induction of late-life sCNDD in fetal cells (Luk et al., 2012b; Morales et al., 2012; Olanow and Brundin, 2013). 
TABLE 1 | Modified from de Pedro-Cuesta et al. (2016) Main biochemical, epidemiologic and other features of sCNDDs and other sporadic human amyloid disorders involved in the proposed etiologic framework.

\begin{tabular}{|c|c|c|c|c|c|c|}
\hline \multirow[t]{2}{*}{$\begin{array}{l}\text { Entity or neuropathologically } \\
\text { related entities }\end{array}$} & \multirow[t]{2}{*}{$\begin{array}{l}\text { Main protein } \\
\text { deposit }\end{array}$} & \multicolumn{2}{|c|}{ Reported outbreaks } & \multicolumn{2}{|c|}{$\begin{array}{l}\text { Annual incidence per million } \\
\text { person-years or } \\
\text { prevalence at death }^{\dagger}\end{array}$} & \multirow[t]{2}{*}{$\mathrm{M} / \mathrm{F}$ ratio } \\
\hline & & & & Sporadic & Genetic & \\
\hline Creutzfeldt-Jakob disease & APrP & vCJD & UK, Ireland, France, Spain & 1 & 0.1 & $1.1 / 1$ \\
\hline $\begin{array}{l}\text { Amyotrophic lateral sclerosis (ALS) and } \\
\text { frontotemporal dementia (FTD) }\end{array}$ & $\begin{array}{l}\text { Ubiquitin, MAPT (tau), } \\
\text { SOD, TDP-43/FUS }\end{array}$ & ALS & $\begin{array}{l}\text { Skaraborg county (Sweden; } \\
\text { Gunnarsson et al., 1996). } \\
\text { US human growth hormone } \\
\text { treated cohort (Irwin et al., 2013) }\end{array}$ & 10 & 1 & $1.5-2 / 1$ \\
\hline $\begin{array}{l}\text { Parkinson's disease (PD), } \\
\text { Lewy body disease (LBD) } \\
\text { and multiple system atrophy (MSA) }\end{array}$ & $\alpha$ synuclein & - & - & 100 & 10 & $\begin{array}{l}1.5-2.5 / 1 \\
\text { for PD }\end{array}$ \\
\hline Alzheimer's disease & $\beta$ amyloid, Tau & - & - & 1000 & 100 & $0.92 / 1$ \\
\hline $\begin{array}{l}\text { Late age-related macular } \\
\text { degeneration (AMD) }\end{array}$ & $\begin{array}{l}\text { EFEMP1 wild-type } \\
\text { (Marmorstein et al., 2002) }\end{array}$ & & - & 1000 & Unknown & $0.95 / 1$ \\
\hline T2 diabetes mellitus (T2DM) & Langerhans Islet peptide & - & - & - & - & - \\
\hline $\begin{array}{l}\text { Sporadic cerebral } \\
\text { amyloid angiopathy }\end{array}$ & $\beta$ amyloid wild-type & - & - & - & - & - \\
\hline $\begin{array}{l}\text { Senile systemic amyloidosis (SSA), } \\
\text { heart failure and myocardial infarction, } \\
\text { aortic aneurism, narrow spinal channel }\end{array}$ & Transthyretin wild-type & - & - & - & $25 \% \geq 85$ years $^{\dagger}$ & - \\
\hline Medin arteriopathy (Peng et al., 2005) & Lactadherin & - & - & - & - & - \\
\hline
\end{tabular}

Transmission among individuals proven for CJD and PD, not for MSA*. From PD patient to fetal grafted cells. Brain extracts of MSA cases transmitted $\alpha$ synuclein proteinopathy to TgM83+/- mice (Prusiner et al., 2015). ${ }^{\dagger}$ For SSA.

- Age-at-exposure related effect is a common characteristic of neurodegeneration induced by neurotropic agents (Fishman et al., 1985). In a 1-methyl-4-phenyl-1,2,3,6tetrahydropyridine (MPTP) parkinsonism model, selective nigral neuronal toxicity in laboratory animals was highest for the older rats and macaques (Langston et al., 1987). This was attributed to age-related neuronal pigmented deposit (relevant for accumulation of metabolic residue and advanced glycation end-products), which increases with age.

- Intracerebral injection of brain extracts containing aggregated $\alpha$-synuclein into young, $\alpha$-synuclein-transgenic mice stimulates the formation of $\alpha$-synuclein lesions in the host (Luk et al., 2012a; Mougenot et al., 2012).

- Experiments on different neurodegenerative disease models supporting prion-like mechanisms (Jucker and Walker, 2013): in seeding experiments with APP mice, the age of the host at the time of inoculation can be a strong determinant of the result (Jucker and Walker, 2013). A similar feature is displayed by the male-mouse castration model of $\mathrm{PD}$, which is only efficient when castration is performed on 4- to 6-week-old mice (Khasnavis et al., 2013).

- MSA, an $\alpha$-synucleinopathy, has recently been transmitted in cell and mouse models (Prusiner et al., 2015).

\section{Theory}

Early- and midlife proteinopathies and late-life sCNDD could be induced or modulated by early-age exposures, regardless of anatomic organs for contact and following a log-linear age-related function. Mimicking age-at-exposure related effects in animal models might be essential for supporting the biological plausibility of epidemiologic observations.

\section{Driver 2. Tridimensional Pattern: Direct Relationships between Age at Peak Incidence (or Age at Clinical Onset), Incidence Magnitude, and Course (Clinical Disease Duration)}

The driver, described on the basis of sCJD, FTD, PD, LBD, AD, and AMD data suggest that:

(a) the duration of the subclinical and clinical courses are related;

(b) low-incidence sCNDD progress rapidly, and those with highest incidence progress slowly; and,

(c) agents (including modifiers) generating aggressive forms might be less frequent or require more susceptibility than those lying behind less severe forms which may display high attack rates, i.e., they will affect large proportions of the population.

\section{Complementary Findings}

- Age at peak age-specific incidence appears to be related to protein propagation, as supported by observations of familial $\mathrm{AD}$, where mean ages at onset are determined by the Ab40/42 ratio (Duering et al., 2005).

- Prion models suggests that a lower prion protein inoculum correlates with a longer incubation period (Gravenor et al., 2003). Slow subclinical and clinical progression might 
correspond to long incubation period from low inoculum exposures in experiments with animal models of prion diseases (Gravenor et al., 2003).

- Acute toxic effects followed by residual effects might better fit MPTP model patterns (Langston et al., 1987) than those suggesting a persistently active etiologic mechanism or multiple hits across the life course.

- After request to authors of recent surveys (Bjornsdottir et al., 2013; Caslake et al., 2014) and positive answer for Icelandic data, normalized reported age-specific incidence and median age-at-onset of MSA in Iceland where plotted at a reported figure for other CNDDs (de Pedro-Cuesta et al., 2015). The MSA incidence curve fitted curves and peak values intermediate between those for $\mathrm{sCJD}$ and PD (Figure 1; Granieri et al., 1991; Gao et al., 1998; Baldereschi et al., 2000; Will et al., 2000; Benito-León et al., 2004; de Lau et al., 2004; Pocchiari et al., 2004; Fang et al., 2009; Chen and Lai, 2010; Steenland et al., 2010; Owen et al., 2012; Bjornsdottir et al., 2013; de Pedro-Cuesta et al., 2015).

\section{Theory}

This driver might point to two distinct etiologic sCNDD forms differentiated by rapid progression, such as SCJD, ALS, and some sporadic rapidly-progressing neurodegenerative dementias
(sRPNDds) with peak onset at age 70-75 years, and disease duration $<3$ years and late-life sCNDD with later age at onset and slower progression. When links with vascular lesions or vascular risk factors (VRF) are considered, sCJD, LBD, AD, and AMD would present and perhaps share vascular protein deposits: this would not, however, apply to FTD, PD and MSA, which are epidemiologically less closely related to VRF. Type 2 diabetes mellitus (T2DM) and vascular disease would be particularly seen in SCNDD (including sRPNDds) with incidence peaking after age 85 years. Prion strains and diverse entry routes would determine the large variation of age at onset in hGHrelated atCJD, vCJD, and SCJD. High incidence of late-onset sCNDD might correspond to high attack rates from ubiquitous or widespread, tiny or low inoculum exposures and the opposite or a combination (low incidence, high inoculum exposures) for midlife-onset sCNDD, i.e., earlier-onset sCJD, ALS and earliestonset sRPNDd may share prion-like entry or spread mechanisms.

\section{Driver 3. Shared, Age-at-Onset Related, Genetic Risk Factors}

We postulate that driver 3 reflects the effect of different genes, which, either separately or by interaction, determine the excess risk of several $\mathrm{sCNDD}$, such as $\mathrm{AD}, \mathrm{CJD}$, and $\mathrm{LBD}$

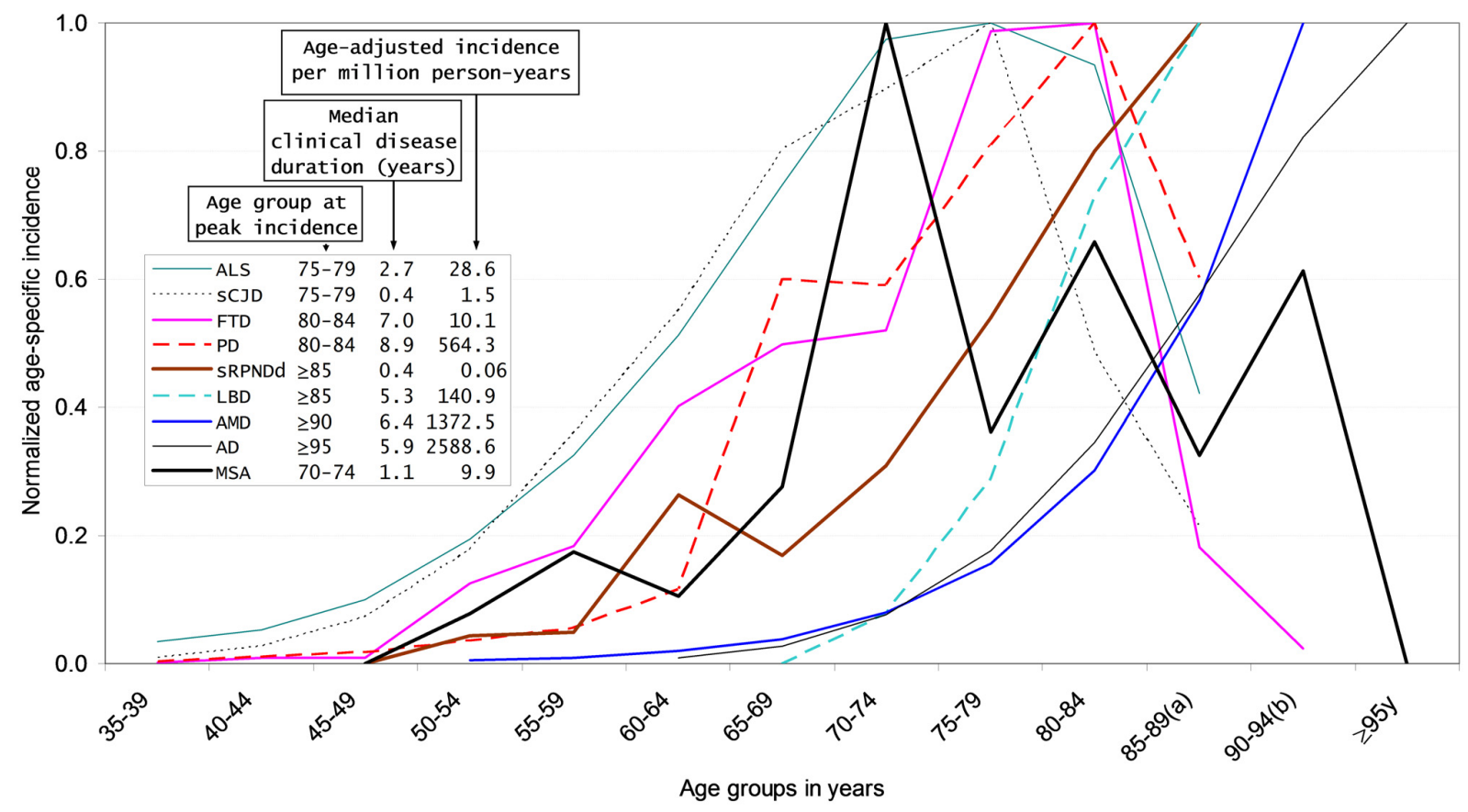

FIGURE 1 | Normalized age-specific incidence, incidence per million and survival for selected neurodegenerative disorders (NDDs). Modified from de Pedro-Cuesta et al. (2015). Normalized age-specific incidence, age-adjusted incidence, and median clinical disease duration of different sporadic protein-associated neurodegenerative disorders (SCNDDs), obtained either from reported data [amyotrophic lateral sclerosis (ALS), personally modified by Fang F, sporadic Creutzfeldt-Jakob disease (sCJD)] or from registries [sporadic rapid progressive neurodegenerative dementia (sRPNDd) notified as suspected sCJD in Spain for 1995-2011, obtained from the Spanish CJD surveillance registry] and obtained from authors for multiple system atrophy (MSA). References for Figure 1 (Granieri et al., 1991; Gao et al., 1998; Baldereschi et al., 2000; Will et al., 2000; Benito-León et al., 2004; Pocchiari et al., 2004; de Lau et al., 2004; Fang et al., 2009; Chen and Lai, 2010; Steenland et al., 2010; Owen et al., 2012; Bjornsdottir et al., 2013). (a) $85-89$ years is equivalent to 85 years and older for sCJD, ALS, Lewy body disease (LBD), Parkinson's disease (PD), and sRPNDd; (b) 90-94 years is equivalent to 90 years and older for age-related macular degeneration (AMD) and frontotemporal dementia (FTD). 
(Wilson et al., 1994; Zende et al., 2013). For instance, positive findings in sCJD and $\mathrm{AD}$ for APOE\&4, CALHM1 and BACE1 polymorphisms underscore the interplay between APP, A $\beta$ oligomers, ApoE, PrP, and BACE1 in sCJD and AD, and suggest that aging may partly modulate disease pathologies through these key players (Calero et al., 2012a,b).

\section{Complementary Findings}

- It is accepted today that the animal models which best reproduce atherothrombotic disease and $\mathrm{AD}$ are those based on ApoE-knockout mice (Zaragoza et al., 2011).

- Diverse reviews on APOE gene effects show that the ApoE4 allele is linked to moderate excess risk for arterial hypertension and ischemic heart disease (Haan and Mayeda, 2010), intracerebral and lobar bleeding (Biffi et al., 2010), coronary heart disease, stroke, peripheral artery disease, and diabetes mellitus (Eichner et al., 2002).

- The common presence of APOE, BACE1 (and other genes, as suggested by total genome studies) linked to $\beta \mathrm{A}$ and other proteins calls for a role for these or other genes in a selected group of sCNDD, as well as in atherosclerosis.

- sCJD was initially misdiagnosed $4 \%$ of times as a vascular, non-autoimmune disease, including stroke (Paterson et al., 2012), perhaps indicating the presence of a vasculopathy in $\mathrm{SCJD}$.

\section{Theory}

APOE4 interacts with etiologic environmental factors for several disorders, i.e., sporadic AD, LBD, AMD, vascular dementia, atherosclerosis, or other forms of vascular disease such as heart failure, myocardial infarction, senile systemic angiopathy, and aortic aneurism. We also hypothesize that shared susceptibility genes for selected sCNDD and atherosclerosis mediate the effects of single pluripotential exposures, i.e., due to the same inoculum, or generated by the same mechanism. High-risk birth cohorts might share excess risk for several conformational disorders.

\section{Driver 4. Personal Risk Factors}

This driver is related to a set of multiple variables, such as clinical signs and symptoms (diagnoses), behavioral patterns (health-related habits), and educational factors, which constitute the group of well-established associations with specific sCNDD. When discussing driver 1 , reference was made to some personal factors potentially due to an age-at-exposure related effect, fitting under the umbrella of developmentally-related effects, i.e., education in $\mathrm{AD}$, cranial perimeter in northKorean women, or early symptoms, such as scoliosis or constipation in PD (Stern et al., 2012). This multifaceted and disperse panorama might be too wide for a satisfactory etiologically oriented approach to sCNDD. Insofar as the focus is $\mathrm{AD}$ or dementia, however, the driver notion constitutes the best structured etiologic and public health approach. A recent review addressing arterial hypertension, T2DM, hypercholesterolemia, physical activity, depression educational attainment, and smoking history (all personal factors) and risk of $\mathrm{AD}$ emphasized the non-independent nature of such factors (Norton et al., 2014). Correcting for dependence, the authors estimated that, assuming causality underlying the associations, the $\mathrm{AD}$ attributable proportion reduced by a control of $10 \%$ of risk factors per decade would be $8.3 \%$ worldwide in 2050 (Norton et al., 2014). When these risk factors were considered with regard to other sCNDD, the established association patterns were weaker. For instance, no excess risk for PD from T2DM was observed, when PD onset was controlled for Simon et al. (2007) and Palacios et al. (2011). In contrast, other studies reported modest increases (Schernhammer et al., 2011; Sun et al., 2012). We believe that the outline shown in Figure 2 (Norton et al., 2014) illustrates the state of art in public health prevention of sCNDD (entity-specific and mainly based on type-4 drivers). We propose that a complementary etiologic overview of sCNDD from personal factors should incorporate goals and interpretations from other drivers, and driver 1 in particular, for late-life $s C N D D$, as illustrated by a potential multiple outcome that combines (though not necessarily in the same individual) protein deposits generating sCNDD, T2DM as a result of Islet amyloid peptide (IAPP), and vascular wall lesions from amyloid deposits such as $A \beta$, lactadherin (Peng et al., 2005) and transthyretin (TTR; Coelho et al., 2013).

\section{Complementary Findings}

- There is increasing biologic evidence supporting the contention that fibrillar amyloid beta protein present in atheroma promotes atherogenesis (Medeiros et al., 2004).

- Bacterial vectors may transport inclusion bodies having amyloid-like properties able to seed their soluble counterparts

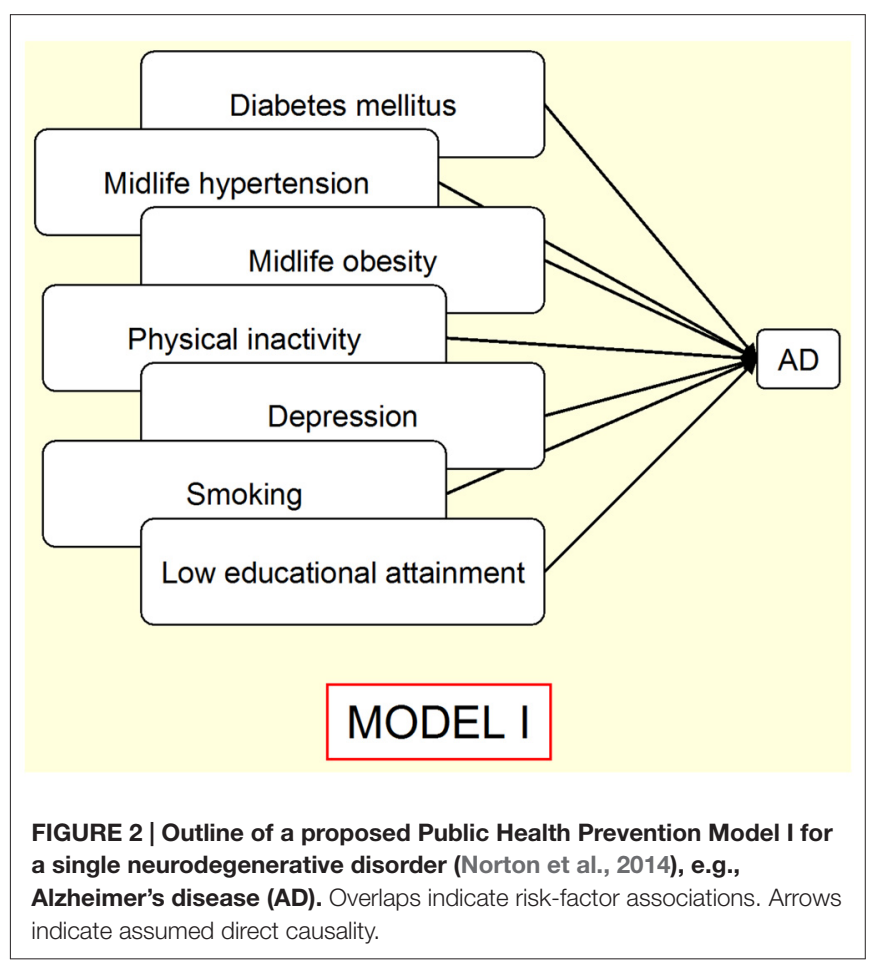


and induce cytotoxicity in eukaryotic cells (for a review see Wang, 2009).

- A growing body of evidence suggests that platelet activation can mediate angiopathy in AD (Zhang et al., 2013). Medindeposits, i.e., lactadherin, underlie age-associated arterial lesions (Peng et al., 2005).

- Colocalization studies of IAPP and A $\beta$ in islet amyloid in type 2 diabetic patients, and $A \beta$ deposits in brains of patients with $\mathrm{AD}$ show heterologous seeding between IAPP and $\mathrm{A} \beta$, a phenomenon that may represent a molecular link between T2DM and AD (Oskarsson et al., 2015).

\section{Theory}

The view based on personal factors and the amyloid perspective on sCNDD suggests that a considerable part of the associations with late-life sCNDD, atherosclerosis, and T2DM might conceal confounding or reverse association (early manifestations of subclinical disease). This view, if confirmed, might complement the rationale for prevention of $\mathrm{SCNDD}, \mathrm{T} 2 \mathrm{DM}$, and part of atherosclerosis, where measures for control of shared etiologic mechanisms underlying sCNDD, T2DM, and various angiopathies are proposed. Driver 4 contribution to theory is summarized as a potential switch of the roles attributed to a direct relationship between risk factors and sCNDD in Figure 2, to those outlined in Figure 3. Most of these associations are in part interpreted as confounding or reverse causality, and direct causality is assigned to a higher level shared by defined amyloid disorders.

\section{Driver 5. Environmental Risk Factors}

As a relevant part of our hypothesis we selected invasive medical procedures (mainly surgery) as a risk factor for sCJD and BP infection as a risk factor for PD.

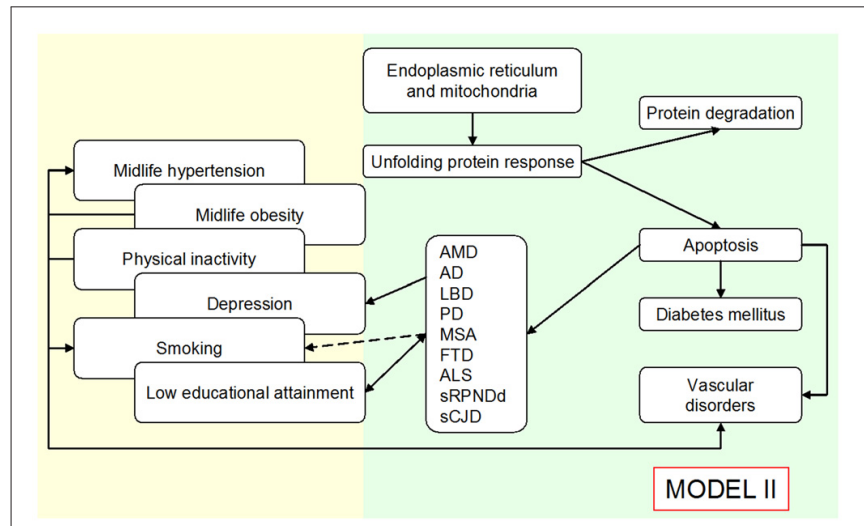

FIGURE 3 | Outline of an expanded Public Health Prevention Model I to Model II, assuming an age-at-onset related continuum for various late-age NDDs, and that the unfolded protein response explains - at least in part-the reported associations for diverse conformational neurodegenerative, vascular degenerative and metabolic disorders (type 2 diabetes mellitus, T2DM). Modified from de Pedro-Cuesta et al. (2016).

\section{Invasive Medical Procedures and Risk of Midlife sCNDD}

The hypothesis of a surgical (and blood-transfusion-related) risk of SCJD is based on a few reports on CJD among patients exposed to neurosurgical instruments used on a patient with subclinical or clinically manifested CJD, and on observations from a register-based population case-control study on routine hospital surgery followed by a lag of over 20 years, with retina surgery being associated with $\mathrm{SCJD}$, on the basis of three cases with a mean latency of 11 years (de PedroCuesta et al., 2011). Aside from one Italian study (Puopolo et al., 2011), however, confounding by surgically-linked blood transfusion was not controlled for, and no positive association between neurosurgical procedures and CJD has been shown. Inconsistent findings for risk from blood transfusion have been reported.

\section{Complementary Findings}

- In 1994, infectivity from tissues such as liver and lung was shown in CJD mouse models (Brown et al., 1994). Subsequently, transmission of prion disease from tissue remnants adhered to surgical instruments was confirmed (Weissmann et al., 2002).

- Injection of mouse brain extract containing $A \beta$ seeds (similar to those found in the $\mathrm{AD}$ brain) into the peritoneal cavity of mice genetically engineered to develop amyloid plaques (murine model of $\mathrm{AD}$ ) accelerates $\mathrm{A} \beta$ deposition in the host brain (Eisele et al., 2010).

- $\beta$ A deposition can be induced by injection of $\mathrm{AD}$ brain extracts into animals, which, without exposure to this material, would never otherwise develop these alterations (Morales et al., 2012).

- An independent line of evidence builds on seeding experiments from curli for E. coli and other organisms in Amyloidosis A (Lundmark et al., 2005).

- The long incubation suggested for sCJD from routine surgery undergone at high-susceptibility ages would suggest that such mechanisms may only be relevant for rapid-course sCNDD, so that the latency period for late-life NDDs might exceed the human life course.

- The increased resistance to protein degradation in amyloid may provide some consistency with prion theory.

- Recently some patients treated with cadaveric hGH who subsequently developed iatrogenic CJD also showed evidence of $\beta$ A deposition in their pituitary glands (Jaunmuktane et al., 2015; Frontzek et al., 2016).

- Brain extracts of MSA cases, in general aged at onset $\leq 75$ years, transmitted an $\alpha$-synuclein proteinopathy to TgM83+/- mice being the prionic nature of some $\alpha$-synuclein recognized (Prusiner et al., 2015).

\section{Theory}

On the basis of register-based epidemiologic studies on surgical risk of sCJD suggesting age-related susceptibility, the suggested associations of ALS and incidence peaking at a similar age, we propose that sCJD, ALS and some sRPNDds and MSA with onset below age 75-79 years are transmitted by routine 
surgery and transfusion of blood or blood derivatives at juvenile age.

\section{Host-Adapted Human Pathogens. BP and Late-Life sCNDD}

The association between age at first major whooping cough outbreak (MWCO) and PD constitutes an important observation in Iceland, reinforced by negative results for birth-cohort effects in continental populations. Considered as a quasi-experiment, it is consistent with the high prevalence and incidence of PD among the Faroe Islanders and Greenland Inuit (Wermuth et al., 2002, 2008). The excess risk of PD as a long-term biological effect of BP infection was attributed to Pertussis toxin (de Pedro-Cuesta et al., 1996). Since PD shares protein deposits (for a review see Sutherland et al., 2011 ) with MSA, LBD, and AD, BP infection in genetically susceptible young individuals might be proposed as an environmental driver for late-life sCNDD such as MSA, PD, $\mathrm{LBD}, \mathrm{AD}$, and AMD.

\section{Complementary findings}

- BP has historically been harbored by human populations and its dynamic still remains uncontrolled by vaccines. Despite the fact that undesired protein aggregation can have negative consequences for the cell, functional aggregationprone regions and aggregates are essential for life. For example, in some enterobacteria, amyloid aggregates appear to mediate bacterial adhesion, biofilm development, and host invasion (de Groot et al., 2012). Human coexistence with commensal or pathogenic bacteria such as BP might have led to the interaction of bacterial aggregated proteins with aggregationprone sequences from the host, resulting in xeno-templating.

- A mutation in the PS2 gene (M239V) neutralizes the toxicity mediated by the Pertussis toxin, suggesting that this toxin shares pathological mechanisms with some AD-mutant variants (Abe et al., 2004).

- Biological agents acting in the distant past may have changed as a result of human interventions, such as vaccination (Cummings et al., 2004).

- Horizontal gene transfer research on the Tohama I strain of BP dating back to 1950 may provide source information for understanding the pathobiology of BP and the potential effect in Japanese cohorts currently aged 70 years (Preston, 2005), particularly if curli can be identified in such strain.

- The rationale suggested for E. coli (see "Driver 7. Invariant ratio of sCNDD Incidence/Genetic CNDD Incidence, Across Entities" Section) would also be valid for BP. Seeding of naturally occurring protein fibrils from $\mathrm{BP}$, as experimentally observed with curli from E. coli (Lundmark et al., 2005), might be hypothesized as biological pluripotential mechanisms underlying $\mathrm{BP}$ infection as a causal factor of $\mathrm{PD}, \mathrm{AD}$, and diverse late-life sCNDD.

- Mechanisms for adaptation to humans seem to have occurred in the $\mathrm{BP}$ precursor, B. pseudopertussis, at an earlier time, taking place for BP by gene loss (Diavatopoulos et al., 2005). B. pertussis infection damages nasal ciliated epithelium, a structure which transfers uranium to brain along olfactory nerve bundles (Wilson et al., 1991; Ibáñez et al., 2014).
- The clear, saw-teeth, birth-cohort pattern seen for PD incidence and attributed to the periodic pattern of $\mathrm{BP}$ epidemics in Iceland suggests that a similar effect of agents, other than airborne BP epidemic agents, such as influenza or measles, is unlikely. However, a supplementary action through the gastrointestinal tract is not ruled out. The shared early loss of olfactory function and lesions described in SCJD, FTD, PD, and $\mathrm{AD}$ might point to a potential effect of $\mathrm{BP}$ infection on the clinical profile of sCNDD (Magerova et al., 2014).

- In addition to airborne agents, synthetic amyloid-like biomaterials and oral agents such as those described for vCJD or food have been proposed, given the high content in protein fibrils (Westermark and Westermark, 2010).

- In accordance with the induction of AApoAII amyloidosis by various amyloid fibrils, though best by mouse AApoAII(C) amyloid (Fu et al., 2004), the expected key active element mediated by the human microbiome might be a natural fibril genetically related to human pathology.

\section{Theory}

Human-adapted agents integrating human genome such as BP able to generate natural protein fibrils might generate different late-life sCNDD by pluripotential mechanisms in accordance with the individual susceptibility. BP may act through nasal and gastrointestinal epithelia. Systemic action across the endoplasmic reticulum (ER) and vascular endothelium might be plausible.

\section{Driver 6. Endoplasmic Reticulum Stressors or General Drivers}

Protein folding is a basic mechanism regulating cell function and survival (Bernales et al., 2012). Variables related to the unfolding protein response (UPR) in ER and mitochondria, acting either as stressors or as a result of altered pathways might be epidemiologically captured, reflecting some of the most characteristic drivers of the expanded NDD paradigm. They may affect sCNDD, T2DM, and atherosclerosis potentially related with senile systemic angiopathy and cerebral amyloid$\beta(\mathrm{A} \beta)$ angiopathy (CAA; linked to myocardial infarction and dementia or $\mathrm{AD}$, respectively), with different underlying amyloid deposits, i.e., wild-type TTR, lactadherin, and beta amyloid. In accordance with the original general proposal, such drivers may affect membrane or secretory tissues such as those resulting in estrogen and testosterone deficits, and midlife VRF such as metabolic syndrome and T2DM. Relationships may be complex if some of the ER stress effects or causes constitute T2DM or sCNDD comorbidity, i.e., obesity.

\section{Complementary Findings}

- The role of endocrine factors in SCNDDs risk is supported by clinical and animal research. Since premenopausal oophorectomy is an iatrogenic factor, at least some associations of estrogen deficit may be considered to act outside the most susceptible lifetime points (driver 1), such as juvenile age.

- In addition to the estrogen deficit in dementia, AD pathology, T2DM, and atherosclerosis discussed elsewhere (de PedroCuesta et al., 2016), an impact on synuclein-related sCNDD 
may be suggested, since some animal studies implicate a role for estrogen in protecting the nigrostriatal dopaminergic functions (Becker, 1990; Morissette and Di Paolo, 1993).

- However, estrogen therapy with esterified estrogen use in combination with progestin was recently linked to a 6-fold excess risk of PD (Lundin et al., 2014). While castration, conducted no later than at 4-5 weeks, makes the malemouse model support the etiologic role of testosterone deficit in PD (Khasnavis et al., 2013), it may also convey insights into the driver-1 effect better than does andropause mimicry.

- The fact that some endocrine deficits, i.e., testosterone, are linked to risk of other endocrine disorders raises questions about a shared, unidentified etiologic cause affecting secretory systems.

- Complex links are suggested for T2DM: T2DM could be also taken as a general driver, since it is associated with risk of both FTD (Golimstok et al., 2014) and AD (Jayaraman and Pike, 2014), and at the same time constitutes an outcome of testosterone depletion (Kapoor et al., 2006; Lage et al., 2007).

- The relationship of ER stress and vascular wall pathology may be persistent, since increased ER stress was identified in atherosclerotic plaques linked to coronary syndrome (Myoishi et al., 2007).

- The UPR in ER may be affected by environmental insults and genetic modifiers which hamper biosynthesis of steroids, cholesterol and many lipids (Kaufman, 2002).

- We believe that the amyloid perspective may serve as a reference for etiologic thinking, where shared determinants of early amyloid deposits in myocardial or cerebral vessels, i.e., the tau/AD pathology (Chui et al., 2012) are plausible. Chronic endocrine disorders such as estrogen or testosterone deficits might not yet have been identified as conformational disorders.

\section{Theory}

Figure 3 depicts a hypothetical etiologic scenario modified from Figure 2, where different amyloid deposits shared by sCNDD, vascular disorders and a number of endocrine entities or functions, determine late-life human pathology as a result of ER stressors or poor UPR. As a complement, some endocrine factors of a different origin (i.e., oophorectomy or specific estrogen therapies) might also constitute risk factors for conformational disorders.

\section{Driver 7. Invariant Ratio of SCNDD Incidence/Genetic CNDD Incidence, Across Entities}

This driver applies basically to genetic CNDDs determined by point mutations. The ratio, best known when defined by a proxy value, namely, the proportion of incident disease corresponding to familial forms, tends to increase due to the progressive improvement in the identification of such mutations, and may reach $25 \%$ in selected sCNDD. This feature, emphasized by Soto and Estrada (2008), has long been recognized, despite the fact that this proportion is higher in a few populations
(Israeli Jews, or populations with genetic clusters, e.g., Slovenia for CJD). Similarly low proportions have been described for genetic vs. sporadic forms of T2DM. The proportion is less clearly perceived for AMD where mutated or wild-type EFEMP1 has been described, and atherosclerosis forms, such as SSA, heart failure and aortic aneurysm (Westermark and Westermark, 2010), where wild-type TTR deposits have been described but an incidence or case series reference for the sporadic form is lacking.

\section{Complementary Findings}

- The ecologic relationship between sporadic genetic forms may suggest a causal link between genetic CNDDs resulting from point mutations and the corresponding sCNDD forms. Since the predominant protein signature of a specific sCNDD frequently corresponds to that of its genetic CNDD form, one might speculate that, ontogenically speaking, sCNDD forms might be considered secondary to genetic ones in terms of numbers and biochemical similarity (Parcerisas et al., 2014).

- In a prior article (de Pedro-Cuesta et al., 2016), we proposed that the most relevant field of knowledge for driver 7 and assessment of the role of vectors in sCNDD might be gene transfer from human to bacterial human pathogens. A first key issue would be the potential of human sequences to make the hosted agent generate misfolded proteins, resulting in infective natural fibrils with a biochemical signature determined by the transferred genetic material. The hypothesis would require an impact on sporadic atherosclerosis of mutations other than those seen in the TTR gene and Notch 1 present in Cerebral Autosomal-Dominant Arteriopathy with Subcortical Infarcts and Leukoencephalopathy (CADASIL), but the high nonspecific potential of natural and synthetic protein fibrils to enhance the amyloid response during inflammation might explain cross-effects (Fu et al., 2004).

- In this essay, we provide an example of such a potential process which might have been identified, namely, that of E. coli. It has been estimated that more than $17 \%$ of the genetic material of E. coli (an enterobacterium hosted by humans; Lawrence and Ochman, 1997), whose curli, natural protein fibrils, have been used in animal models of A-amyloidosis by natural fibril-seeding, is the result of horizontally transferred, protein-coding DNA over several million years (Lawrence and Ochman, 1997; Lundmark et al., 2005).

- Since inflammation is required for templating, the role of E. coli might be mediated by gastrointestinal infections at a young age. In 2003, Braak and associates proposed that transneuronal transmission of pathologically altered $\alpha$-synuclein from the enteric nervous system to the brainstem might occur in PD (Braak et al., 2003). Various heterogeneous, natural and synthetic amyloid fibrils induced AApoAII amyloidosis (Fu et al., 2004). This process could be compatible with a proportion of cases being determined by other mechanisms or entry sites such as the oral cavity (Olsen and Singhrao, 2015). In contrast, SB Prusiner suggests that the late onset of heritable NDDs, like their sporadic counterparts, 
may reflect a stochastic nature of prion formation (Prusiner, 2013).

- Based on epidemiologic and laboratory research, it has been proposed that several infectious agents are linked to different NDDs: Nocardia sp. and BP to parkinsonism (Kohbata and Beaman, 1991; de Pedro-Cuesta et al., 1996), and recent adeno-associated viral vectors provide excellent $\alpha$-synuclein models of PD (Lindgren et al., 2012). Similarly, Herpes simplex virus type 1 (HSV-1), in conjunction with apolipoprotein E4 (ApoE4) from a murine acute infection model, has recently been proposed as a risk factor for AD (Burgos et al., 2006; Harris and Harris, 2015). A similar relationship has been suggested for fungal infection and AD or ALS (Alonso et al., 2015a,b; Pisa et al., 2015a,b). The field of potential vectors, if restricted to well-adapted human pathogens, remains yet undefined but many are already sequenced.

\section{Theory}

Curli from some human-adapted pathogens correspond to multiple potentially infective natural misfolded protein fibrils resulting from horizontal gene transfer (HGT) from agents well adapted to the human host, acting at young ages as pluripotential agents facilitating invasion, particularly during inflammatory conditions (infections). These mechanisms may be shared by some angiopathies and T2DM exhibiting a similar driver, as well as by multiple similar pathogenic processes among humans. An essential condition for bacterial agents being candidates for HGT is that they themselves or their close ancestors must have been well adapted to human hosts by integrating pathogenic DNA (deoxyribonucleic acid) from different niches (gingival, nasal, respiratory mucosae or gut epithelium, and other). In essence, infection by $E$. coli or coexistent with E. coli as a part of the intestinal microbiome, and other well adapted human hosts carrying pathogenic human genetic material and natural protein fibrils might induce diverse sCNDD, T2DM, and atherosclerosis, following an age-atinfection pattern.

\section{MAIN FEATURES OF A CAUSAL HYPOTHESIS FOR SCNDD, ATHEROSCLEROSIS, AND T2DM}

We propose that $\mathrm{sCNDD}, \mathrm{T} 2 \mathrm{DM}$, a relevant proportion of atherosclerosis, as well as other late-life endocrine disorders resulting in andropause and estrogen deficit, constitute organlimited amyloid disorders, where conformational mimicry leads to misfolding of a limited number of proteins such as PrP, Langerhans Islet peptide, amyloid beta $(\mathrm{A} \beta)$, tau, $\alpha$ synuclein, SOD1, FTP-43, medin, TTR, and wild-type EFMP1 (Marmorstein et al., 2002).

Initial biological mechanisms are rooted in human genomics. Eukaryotic DNA fragments implicated in genetic forms of late-life NDDs [mainly AP and PD] incorporated in the genome of potential commensal, symbiotic, and pathogenic microorganisms present in the human reservoir, i.e., E. coli and $\mathrm{BP}$, constitute sequences resulting in pluripotential protein fibrils that are infective via the respiratory and gastrointestinal tract or by B lymphocyte presentation. Some amyloid proteins such as APrP may additionally act parenterally by contact with human misfolded protein fibrils, generating rapid course sCNDD, such as SCJD, ALS, and some sRPNDds. Disease progression and spread through the central nervous system would follow reported anatomic patterns. Early vascular-wall lesions determine the first steps in atherosclerotic plaque formation. Small-vessel and neuronal lesions frequently coexist. The same pathogenic mechanisms may underlie some endocrine disorders. Multiple degenerative disorders may share conformational pathophysiologic mechanisms linked to different, as yet unknown, UPR. Latency intervals might frequently encompass decades.

sCNDD epidemiologic patterns point to a high susceptibility in late-infancy and at juvenile ages. Risk and disease spread can be determined by the same factors, which constitute risk factors or biomarkers of disease progression, or both. ER stressors and UPR-related pathology, particularly late in life, may display complex relationships, i.e., as seen for VRF, late-life sCNDD, atherosclerosis, and T2DM. Incorporation of drivers 5,6, and 7 in the model seen in Figure 3, would result in a comprehensive etiologic model presented in Figure 4.

\section{IMPLICATIONS FOR RESEARCH}

Components of the model seen in Figure 4 would have implications for cohort alignment and experimental animal research, as well as a for specific research outline proposals aimed to test fragments of the abovementioned hypothesis.

\section{Cohort Alignment}

The present view of sCNDD reinforces the notion of a set of neurodegenerative processes in which continuity as a form of overlap, and competition-earlier and more lethal NDDs, T2DM or vascular disease removing persons at high risk of other less lethal NDDs-act on the age axis. Equivalent, observational,

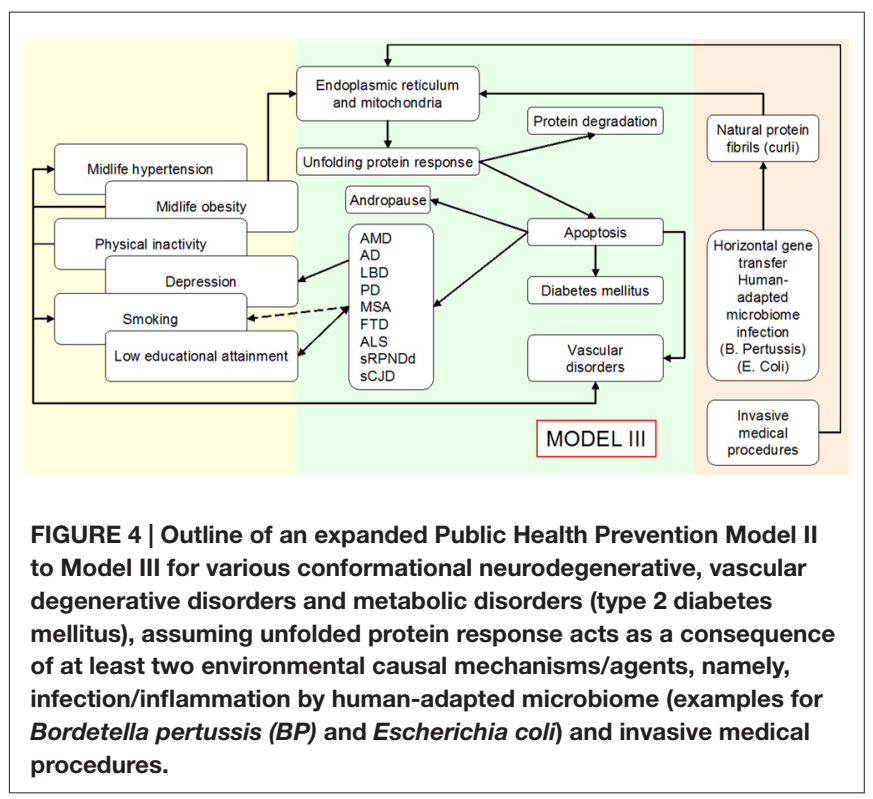


proof-of-principle studies would correspond to investigations aimed at confirming that NDDs which are clinically and epidemiologically close by median age at onset, disease duration, age-specific normalized incidence profile and genetic type of change, share environmental risk factors. The study of exposures in the first two decades of life would require approaches separated from that of the same exposures at later ages, with latency analyses being needed in both instances. Simultaneous approaches including two or more NDDs may be advantageous. Identification of selected populations by criteria targeted at optimizing ascertainment of both exposure and outcome, plus identification of randomly selected population controls are paramount.

\section{Experimental Animal Research}

Implications of the driver notion from sCNDD epidemiology in experimental research appear to be less direct than in cohort alignment, requiring translation to biological inference. Different animal models have been developed to address various sCNDD, cardiovascular disease complications, and T2DM. Models in mice targeting AD, tauopathies, and ALS are mainly based on transgenic methodologies, with those for PD and synucleinopathies being both toxic and transgenic. Animal models may exhibit a number of important limitations, mimicking phenotypic variants of $\mathrm{AD}$ and other $\mathrm{sCNDD}^{1}$. The validity of human drivers, i.e., age-at-exposure related susceptibility, may be tested in toxic animal models of NDD.

In general, little attention has been paid to diseasenon-specific animal models based on seeding of naturally produced amyloid fibrils, such as those generated by Sup35 from Saccharomyces cerevisiae, and curli from E. coli which exert amyloid-accelerating influences in experimental murine amyloidosis (Lundmark et al., 2005). In contrast, the validity of traditional approaches is extensively considered in diseaseoriented media. A human driver-1-related, ApoE -/- mouse model, is that which best fits the study of arteriosclerosis and diabetes-accelerated arteriosclerosis (Zaragoza et al., 2011). A similar feature displays the male-mouse castration model of PD (Khasnavis et al., 2013). It would appear that the most valid NDD models are the genetically-modified, cell and animal models of AD, PD, FTD, and ALS, all of which are based on the mutations described in the familial NDD forms ${ }^{2}$. A research goal in the experimental model context might be the identification of key elements underlying an environmentally modified, potential effect of human genes, similar to that shown by laboratory experiments on NDDs, T2DM and atherosclerosis with traditional models.

Specific attempts to combine population and clinical cohorts/registries able to trace human events determining current disease might be a priority, particularly if: (a) such events

\footnotetext{
${ }^{1}$ http://www.neurodegenerationresearch.eu/initiatives/jpnd-alignmentactions/animal-and-cell-models.

${ }^{2}$ http://www.neurodegenerationresearch.eu/initiatives/jpnd-alignmentactions/animal-and-cell-models.
}

can be identified by drivers; and (b) agents, similar to natural fibrils used in seeding models reproducing amyloid disease including NDDs, can be identified from historical sources, banks or libraries.

\section{NOTIONS FOR RESEARCH FRAMEWORK DEVELOPMENT}

\section{Epidemiology}

Traditionally, neuroepidemiologists have been used to working with surveys or cohorts geographically settled close to their residence. As a novelty, assessment and alignment of cohorts for specific research purposes might be done for the first time with a high number of population or clinical cohorts gathered and offered as a potentially shared research resource ${ }^{3}$. On the basis of best clinical and epidemiologic practice, research into this avenue mighty advantageously address the etiology of and risk factors for sporadic forms of CJD, sRPNDd, MND, MSA, LBD, FTD, PD, AD, and AMD. This would require work on populations exposed to biological environments in specific conditions and with exposures measured under extremely favorable conditions for epidemiologic comparisons pertaining to registration and the time lag after exposure. Only a few populations in the world would allow for such field studies. To avoid misclassification of outcomes (subclinically affected controls), studies on the very old should be extremely cautious.

Possible factors to be weighted when considering favorable research environments are:

- Populations with registered data on both sRPNDd and sCJD tend to be large countries where CJD surveillance has been conducted for decades, and NDD- as well as CJD-free clinical controls have been registered.

- Medical procedures can be advantageously studied in countries with national health services that provide health care for the majority of their citizens.

- Controls randomly selected from annual population registries are paramount for studies on risk from medical procedures.

- Historically, populations exposed to agents producing point-source epidemics which are considerably separated in time and act on the young population, have been those that are geographically isolated with ancient native populations $<200,000$. A minimum size or pooled study would be required for substantial incidence counts of late-life NDDs. Study populations of this nature are to be found in Iceland, New Caledonia, San Miguel in the Azores (AleixoDias et al., 1993), and a few other islands.

- In order to reveal the causal nature of specific associations, it might be advantageous to study the synergistic effects observed between environmental exposures and selected recognized genetic risk factors for different entities.

\footnotetext{
${ }^{3} \mathrm{http} / /$ www.neurodegenerationresearch.eu/initiatives/jpnd-alignmentactions/longitudinal-cohorts/.
} 


\section{Experimental Work}

Research of this nature might encompass:

- Identification of potential agents (well adapted, small genome) with biological samples in potential vector libraries worldwide, in cases where such agents are implicated in NDD incident in high-risk cohorts;

- In silico identification of human genome fragments in vectors exhibiting curly or natural fibrils potentially involved in NDD induction, as seen from analysis of specific cohorts;

- Protein aggregate characterization in biological samples (bacteria, etc.), work with biofilms; and,

- development of animal models of defined or undefined amyloid disorders, based on the seeding of natural fibrils potentially involved in NDD induction.

\section{AUTHOR CONTRIBUTIONS}

JdP-C conceived and coordinated the study, analyzed literature, wrote first manuscript version. PM-M analyzed clinical literature and animal models reports, and contributed with comments. AR contributed with neuropathology literature and comments. MR-T revised aspects on prion disorders and provided comments. EA-C updated statistical calculations on incidences, and designed graphs. MC analyzed biochemical, genetic and molecular literature; revised in detail the manuscript and added comments. All authors read and approved the final manuscript version.

\section{REFERENCES}

Abe, Y., Hashimoto, Y., Tomita, Y., Terashita, K., Aiso, S., Tajima, H., et al. (2004). Cytotoxic mechanisms by M239V presenilin 2, a little-analyzed Alzheimer's disease-causative mutant. J. Neurosci. Res. 77, 583-595. doi: 10.1002/jnr. 20163

Aleixo-Dias, J., de Pedro-Cuesta, J., López-Abente, G., Vasconcelos, J., Lopes, J., and Santos, J. (1993). Tosse convulsa e doença de Parkinson. Estudo de uma possivel associaçao. Saúde em Números 8, 33-37.

Alonso, R., Pisa, D., Marina, A. I., Morato, E., Rábano, A., Rodal, I., et al. (2015a). Evidence for fungal infection in cerebrospinal fluid and brain tissue from patients with amyotrophic lateral sclerosis. Int. J. Biol. Sci. 11, 546-558. doi: 10. 7150/ijbs. 11084

Alonso, R., Pisa, D., Rábano, A., Rodal, I., and Carrasco, L. (2015b). Cerebrospinal fluid from Alzheimer's disease patients contains fungal proteins and DNA. J. Alzheimers Dis. 47, 873-876. doi: 10.3233/JAD-150382

Baldereschi, M., Di Carlo, A., Rocca, W. A., Vanni, P., Maggi, S., Perissinotto, E., et al. (2000). Parkinson's disease and parkinsonism in a longitudinal study: twofold higher incidence in men. ILSA Working group. italian longitudinal study on aging. Neurology 55, 1358-1363. doi: 10.1212/wnl.55.9.1358

Barlow, B. K., Cory-Slechta, D. A., Richfield, E. K., and Thiruchelvam, M. (2007). The gestational environment and Parkinson's disease: evidence for neurodevelopmental origins of a neurodegenerative disorder. Reprod. Toxicol. 23, 457-470. doi: 10.1016/j.reprotox.2007.01.007

Becker, J. B. (1990). Direct effect of $17 \beta$-estradiol on striatum: sex differences in dopamine release. Synapse 5, 157-164. doi: 10.1002/syn.8900 50211

Benito-León, J., Bermejo-Pareja, F., Morales-González, J. M., Porta-Etessam, J., Trincado, R., Vega, S., et al. (2004). Incidence of Parkinson disease and parkinsonism in three elderly populations of central Spain. Neurology 62, 734-741. doi: 10.1212/01.WNL.0000113727.73153.68

\section{FUNDING}

Funding was received from the Consortium for Biomedical Research in Neurodegenerative Diseases (Centro de Investigación Biomédica en Red sobre Enfermedades Neurodegenerativas/CIBERNED) as part of the 2014-2015 annual budget of the CIBERNED 509-group, and from the Carlos III Institute of Health (PI12/00045). Mr. Alcalde received support from the ISCIII Field Epidemiology Program during 2014 and 2015. The study was partially supported by a grant from the EU Joint Program-Neurodegenerative Disease Research (JPND_DEMTEST (Spanish Health Research Fund, FIS PI11/03021)). The funders had no role in study design, data collection and analysis, decision to publish, or preparation of the manuscript. No author other than EAC received specific funding for this work.

\section{ACKNOWLEDGMENTS}

The authors would like to thank the following: Dr. Fang Fang, Karolinska Institute, Stockholm, for personally modifying, reported data on motor neuron disease; Anna Björnsdóttir, Department of Neurology, UMass Memorial Medical Center for individual data on MSA incident patients reported at the Icelandic survey; Fernando Jose Garcia Lopez, National Center for Epidemiology, for his comments on and review of the manuscript; and Javier Almazan and Fuencisla Avellanal for data management at the Spanish CJD Surveillance Registry.

Bernales, S., Soto, M. M., and McCullagh, E. (2012). Unfolded protein stress in the endoplasmic reticulum and mitochondria: a role in neurodegeneration. Front Aging Neurosci. 4:5. doi: 10.3389/fnagi.2012.00005

Biffi, A., Sonni, A., Anderson, C. D., Kissela, B., Jagiella, J. M., Schmidt, H., et al. (2010). Variants at APOE influence risk of deep and lobar intracerebral hemorrhage. Ann. Neurol. 68, 934-943. doi: 10.1002/ana.22134

Bjornsdottir, A., Gudmundsson, G., Blondal, H., and Olafsson, E. (2013). Incidence and prevalence of multiple system atrophy: a nationwide study in Iceland. J. Neurol. Neurosurg. Psychiatry 84, 136-140. doi: 10.1136/jnnp-2012302500

Braak, H., Rub, U., Gai, W. P., and Del Tredici, K. (2003). Idiopathic Parkinson's disease: possible routes by which vulnerable neuronal types may be subject to neuroinvasion by an unknown pathogen. J. Neural Transm. (Vienna) 110 , 517-536. doi: 10.1007/s00702-002-0808-2

Brown, P., Gibbs, C. J. Jr., Rodgers-Johnson, P., Asher, D. M., Sulima, M. P., Bacote, A., et al. (1994). Human spongiform encephalopathy: the national institutes of health series of 300 cases of experimentally transmitted disease. Ann. Neurol. 35, 513-529. doi: 10.1002/ana.410350504

Burgos, J. S., Ramírez, C., Sastre, I., and Valdivieso, F. (2006). Effect of apolipoprotein $\mathrm{E}$ on the cerebral load of latent herpes simplex virus type 1 DNA. J. Virol. 80, 5383-5387. doi: 10.1128/jvi.00006-06

Calero, O., Bullido, M. J., Clarimon, J., Frank-García, A., Martínez-Martín, P., Lleo, A., et al. (2012a). A common BACE1 polymorphism is a risk factor for sporadic creutzfeldt-jakob disease. PLoS One 7:e43926. doi: 10.1371/journal. pone.0043926

Calero, O., Bullido, M. J., Clarimon, J., Hortiguela, R., Frank-García, A., MartínezMartín, P., et al. (2012b). Genetic variability of the gene cluster CALHM 1-3 in sporadic creutzfeldt-jakob disease. Prion 6, 407-412. doi: 10.4161/pri.20785

Caslake, R., Taylor, K., Scott, N., Harris, C., Gordon, J., Wilde, K., et al. (2014). Age- and gender-specific incidence of vascular parkinsonism, progressive supranuclear palsy and parkinsonian-type multiple system atrophy in North 
East Scotland: the PINE study. Parkinsonism Relat. Disord. 20, 834-839. doi: 10. 1016/j.parkreldis.2014.04.013

Chen, Y. Y., and Lai, C. H. (2010). Nationwide population-based epidemiologic study of Huntington's disease in taiwan. Neuroepidemiology 35, 250-254. doi: $10.1159 / 000319462$

Chui, H. C., Zheng, L., Reed, B. R., Vinters, H. V., and Mack, W. J. (2012). Vascular risk factors and Alzheimer's disease: are these risk factors for plaques and tangles or for concomitant vascular pathology that increases the likelihood of dementia? An evidence-based review. Alzheimers Res. Ther. 4:1. doi: 10. 1186/alzrt98

Coelho, T., Maurer, M. S., and Suhr, O. B. (2013). THAOS - The Transthyretin Amyloidosis Outcomes Survey: initial report on clinical manifestations in patients with hereditary and wild-type transthyretin amyloidosis. Curr. Med. Res. Opin. 29, 63-76. doi: 10.1185/03007995.2012.754348

Cummings, C. A., Brinig, M. M., Lepp, P. W., van de Pas, S., and Relman, D. A. (2004). Bordetella species are distinguished by patterns of substantial gene loss and host adaptation. J. Bacteriol. 186, 1484-1492. doi: 10.1128/jb.186.5.14841492.2004

de Groot, N., Torrent, M., Villar-Piqué, A., Lang, B., Ventura, S., Gsponer, J., et al. (2012). Evolutionary selection for protein aggregation. Biochem. Soc. Trans. 40, 1032-1037. doi: 10.1042/bst201 20160

de Lau, L. M., Giesbergen, P. C., de Rijk, M. C., Hofman, A., Koudstaal, P. J., and Breteler, M. M. (2004). Incidence of parkinsonism and Parkinson disease in a general population: the rotterdam study. Neurology 63, 1240-1244. doi: 10 . 1212/01.WNL.0000140706.52798.be

de Pedro-Cuesta, J., Gudmundsson, G., Abraira, V., Gudmundsson, G., Löve, A., Tulinius, H., et al. (1996). Whooping cough and Parkinson's disease. The europarkinson preparatory activity research group. Int. J. Epidemiol. 25, 1301-1311. doi: 10.1093/ije/25.6.1301

de Pedro-Cuesta, J., Mahíllo-Fernández, I., Rábano, A., Calero, M., Cruz, M., Siden, A., et al. (2011). Nosocomial transmission of sporadic Creutzfeldt-Jakob disease: results from a risk-based assessment of surgical interventions. J. Neurol. Neurosurg. Psychiatry 82, 204-212. doi: 10.1136/jnnp.2009.188425

de Pedro-Cuesta, J., Martínez-Martín, P., Rábano, A., Alcalde-Cabero, E., García López, F. J., Almazán-Isla, J., et al. (2016). Drivers: a biologically contextualized, cross-inferential view of the epidemiology of neurodegenerative disorders. J. Alzheimers Dis. 51, 1003-1022. doi: 10.3233/JAD-150884

de Pedro-Cuesta, J., Rábano, A., Martínez-Martín, P., Ruiz-Tovar, M., AlcaldeCabero, E., Almazán-Isla, J., et al. (2015). Comparative incidence of conformational, neurodegenerative disorders. PLoS One 10:e0137342. doi: 10. 1371/journal.pone.0137342

Diavatopoulos, D. A., Cummings, C. A., Schouls, L. M., Brinig, M. M., Relman, D. A., and Mooi, F. R. (2005). Bordetella pertussis, the causative agent of whooping cough, evolved from a distinct, human-associated lineage of B. bronchiseptica. PLoS Pathog. 1:e45. doi: 10.1371/journal.ppat.00 10045

Duering, M., Grimm, M. O., Grimm, H. S., Schröder, J., and Hartmann, T. (2005). Mean age of onset in familial Alzheimer's disease is determined by amyloid $\beta$ 42. Neurobiol. Aging 26, 785-788. doi: 10.1016/j.neurobiolaging.2004. 08.002

Eichner, J. E., Dunn, S. T., Perveen, G., Thompson, D. M., Stewart, K. E., and Stroehla, B. C. (2002). Apolipoprotein E polymorphism and cardiovascular disease: a HuGE review. Am. J. Epidemiol. 155, 487-495. doi: 10.1093/aje/155. 6.487

Eisele, Y. S., Obermüller, U., Heilbronner, G., Baumann, F., Kaeser, S. A., Wolburg, H., et al. (2010). Peripherally applied A $\beta$-containing inoculates induce cerebral $\beta$-amyloidosis. Science 330, 980-982. doi: 10.1126/science. 1194516

Fang, F., Valdimarsdottir, U., Bellocco, R., Ronnevi, L. O., Sparén, P., Fall, K., et al. (2009). Amyotrophic lateral sclerosis in Sweden, 1991-2005. Arch. Neurol. 66, 515-519. doi: 10.1001/archneurol.2009.13

Fishman, P. S., Gass, J. S., Swoveland, P. T., Lavi, E., Highkin, M. K., and Weiss, S. R. (1985). Infection of the basal ganglia by a murine coronavirus. Science 229, 877-879. doi: 10.1126/science.2992088

Frontzek, K., Lutz, M. I., Aguzzi, A., Kovacs, G. G., and Budka, H. (2016). Amyloid- $\beta$ pathology and cerebral amyloid angiopathy are frequent in iatrogenic Creutzfeldt-Jakob disease after dural grafting. Swiss Med. Wkly. 146:w14287. doi: 10.4414/smw.2016.14287
Fu, X., Korenaga, T., Fu, L., Xing, Y., Guo, Z., Matsushita, T., et al. (2004). Induction of AApoAII amyloidosis by various heterogeneous amyloid fibrils. FEBS Lett. 563, 179-184. doi: 10.1016/s0014-5793(04)00295-9

Gao, S., Hendrie, H. C., Hall, K. S., and Hui, S. (1998). The relationships between age, sex and the incidence of dementia and Alzheimer disease: a meta-analysis. Arch. Gen. Psychiatry 55, 809-815. doi: 10.1001/archpsyc.55.9.809

Golimstok, A., Cámpora, N., Rojas, J. I., Fernández, M. C., Elizondo, C., Soriano, E., et al. (2014). Cardiovascular risk factors and frontotemporal dementia: a case-control study. Transl. Neurodegener. 3:13. doi: 10.1186/20479158-3-13

Granieri, E., Carreras, M., Casetta, I., Govoni, V., Tola, M. R., Paolino, E., et al. (1991). Parkinson's disease in Ferrara, Italy, 1967 through 1987. Arch. Neurol. 48, 854-857. doi: 10.1001/archneur.1991.00530200096026

Gravenor, M. B., Stallard, N., Curnow, R., and McLean, A. R. (2003). Repeated challenge with prion disease: the risk of infection and impact on incubation period. Proc. Natl. Acad. Sci. U S A 100, 10960-10965. doi: 10.1073/pnas. 1833677100

Gunnarsson, L. G., Lygner, P. E., Veiga-Cabo, J., and de Pedro-Cuesta, J. (1996). An epidemic-like cluster of motor neuron disease in a Swedish county during the period 1973-1984. Neuroepidemiology 15, 142-152. doi: 10.1159/000 109901

Haan, M. N., and Mayeda, E. R. (2010). Apolipoprotein E genotype and cardiovascular diseases in the elderly. Curr. Cardiovasc. Risk Rep. 4, 361-368. doi: 10.1007/s12170-010-0118-4

Harris, S. A., and Harris, E. A. (2015). Herpes simplex virus type 1 and other pathogens are key causative factors in sporadic Alzheimer's disease. J. Alzheimers Dis. 48, 319-353. doi: 10.3233/JAD-142853

Ibáñez, C., Suhard, D., Tessier, C., Delissen, O., Lestaevel, P., Dublineau, I., et al. (2014). Intranasal exposure to uranium results in direct transfer to the brain along olfactory nerve bundles. Neuropathol. Appl. Neurobiol. 40, 477-488. doi: 10.1111/nan.12061

Irwin, D. J., Abrams, J. Y., Schonberger, L. B., Leschek, E. W., Mills, J. L., Lee, V. M., et al. (2013). Evaluation of potential infectivity of alzheimer and parkinson disease proteins in recipients of cadaver-derived human growth hormone. JAMA Neurol. 70, 462-468. doi: 10.1001/jamaneurol.2013.1933

Jaunmuktane, Z., Mead, S., Ellis, M., Wadsworth, J. D., Nicoll, A. J., Kenny, J., et al. (2015). Evidence for human transmission of amyloid- $\beta$ pathology and cerebral amyloid angiopathy. Nature 525, 247-250. doi: 10.1038/nature15369

Jayaraman, A., and Pike, C. J. (2014). Alzheimer's disease and type 2 diabetes: multiple mechanisms contribute to interactions. Curr. Diab. Rep. 14:476. doi: 10.1007/s11892-014-0476-2

Jucker, M., and Walker, L. C. (2013). Self-propagation of pathogenic protein aggregates in neurodegenerative diseases. Nature 501, 45-51. doi: 10 1038/nature 12481

Kapoor, D., Goodwin, E., Channer, K. S., and Jones, T. H. (2006). Testosterone replacement therapy improves insulin resistance, glycaemic control, visceral adiposity and hypercholesterolaemia in hypogonadal men with type 2 diabetes. Eur. J. Endocrinol. 154, 899-906. doi: 10.1530/eje.1.02166

Kaufman, R. J. (2002). Orchestrating the unfolded protein response in health and disease. J. Clin. Invest. 110, 1389-1398. doi: 10.1172/jci0216886

Khasnavis, S., Ghosh, A., Roy, A., and Pahan, K. (2013). Castration induces Parkinson disease pathologies in young male mice via inducible nitricoxide synthase. J. Biol. Chem. 288, 20843-20855. doi: 10.1074/jbc.M112. 443556

Kohbata, S., and Beaman, B. L. (1991). L-dopa-responsive movement disorder caused by Nocardia asteroides localized in the brains of mice. Infect. Immun. 59, 181-191.

Lage, M. J., Barber, B. L., and Markus, R. A. (2007). Association between androgendeprivation therapy and incidence of diabetes among males with prostate cancer. Urology 70, 1104-1108. doi: 10.1016/j.urology.2007.08.012

Langston, J. W., Irwin, I., and DeLanney, L. E. (1987). The biotransformation of MPTP and disposition of MPP+: the effects of aging. Life Sci. 40, 749-754. doi: 10.1016/0024-3205(87)90302-x

Lawrence, J. G., and Ochman, H. (1997). Amelioration of bacterial genomes: rates of change and exchange. J. Mol. Evol. 44, 383-397. doi: 10.1007/pl00006158

Lindgren, H. S., Lelos, M. J., and Dunnett, S. B. (2012). Do $\alpha$-synuclein vector injections provide a better model of Parkinson's disease than the classic 6hydroxydopamine model? Exp. Neurol. 237, 36-42. doi: 10.1016/j.expneurol. 2012.05.022 
Luk, K. C., Kehm, V., Carroll, J., Zhang, B., O’Brien, P., Trojanowski, J. Q., et al. (2012a). Pathological $\alpha$-synuclein transmission initiates Parkinson-like neurodegeneration in nontransgenic mice. Science 338, 949-953. doi: 10. $1126 /$ science. 1227157

Luk, K. C., Kehm, V. M., Zhang, B., O’Brien, P., Trojanowski, J. Q., and Lee, V. M. (2012b). Intracerebral inoculation of pathological $\alpha$-synuclein initiates a rapidly progressive neurodegenerative $\alpha$-synucleinopathy in mice. J. Exp. Med. 209, 975-986. doi: 10.1084/jem.20112457

Lundin, J. I., Ton, T. G., LaCroix, A. Z., Longstreth, W. T., Franklin, G. M., Swanson, P. D., et al. (2014). Formulations of hormone therapy and risk of Parkinson's disease. Mov. Disord. 29, 1631-1636. doi: 10.1002/mds. 26037

Lundmark, K., Westermark, G. T., Olsén, A., and Westermark, P. (2005). Protein fibrils in nature can enhance amyloid protein A amyloidosis in mice: crossseeding as a disease mechanism. Proc. Natl. Acad. Sci. U S A 102, 6098-6102. doi: 10.1073/pnas.0501814102

Magerova, H., Vyhnalek, M., Laczo, J., Andel, R., Rektorova, I., Kadlecova, A., et al. (2014). Odor identification in frontotemporal lobar degeneration subtypes. Am. J. Alzheimers Dis. Other Demen. 29, 762-768. doi: 10. $1177 / 1533317514539033$

Marmorstein, L. Y., Munier, F. L., Arsenijevic, Y., Schorderet, D. F., McLaughlin, P. J., Chung, D., et al. (2002). Aberrant accumulation of EFEMP1 underlies drusen formation in Malattia Leventinese and age-related macular degeneration. Proc. Natl. Acad. Sci. U S A 99, 13067-13072. doi: 10.1073/pnas. 202491599

Medeiros, L. A., Khan, T., El Khoury, J. B., Pham, C. L., Hatters, D. M., Howlett, G. J., et al. (2004). Fibrillar amyloid protein present in atheroma activates CD36 signal transduction. J. Biol. Chem. 279, 10643-10648. doi: 10. 1074/jbc.M311735200

Morales, R., Durán-Aniotz, C., Castilla, J., Estrada, L. D., and Soto, C. (2012). De novo induction of amyloid- $\beta$ deposition in vivo. Mol. Psychiatry 17, 1347-1353. doi: $10.1038 / \mathrm{mp} .2011 .120$

Morissette, M., and Di Paolo, T. (1993). Effect of chronic estradiol and progesterone treatments of ovariectomized rats on brain dopamine uptake sites. J. Neurochem. 60, 1876-1883. doi: 10.1111/j.1471-4159.1993. tb13415.x

Mougenot, A. L., Nicot, S., Bencsik, A., Morignat, E., Verchère, J., Lakhdar, L., et al. (2012). Prion-like acceleration of a synucleinopathy in a transgenic mouse model. Neurobiol. Aging 33, 2225-2228. doi: 10.1016/j.neurobiolaging.2011.06. 022

Myoishi, M., Hao, H., Minamino, T., Watanabe, K., Nishihira, K., Hatakeyama, K., et al. (2007). Increased endoplasmic reticulum stress in atherosclerotic plaques associated with acute coronary syndrome. Circulation 116, 1226-1233. doi: 10. 1161/circulationaha.107.728378

Norton, S., Matthews, F. E., Barnes, D. E., Yaffe, K., and Brayne, C. (2014). Potential for primary prevention of Alzheimer's disease: an analysis of population-based data. Lancet Neurol. 13, 788-794. doi: 10.1016/S14744422(14)70136-X

Olanow, C. W., and Brundin, P. (2013). Parkinson's disease and $\alpha$ synuclein: is Parkinson's disease a prion-like disorder? Mov. Disord. 28, 31-40. doi: 10. 1002/mds. 25373

Olsen, I., and Singhrao, S. K. (2015). Can oral infection be a risk factor for Alzheimer's disease? J. Oral Microbiol. 7:29143. doi: 10.3402/jom.v7. 29143

Oskarsson, M. E., Paulsson, J. F., Schultz, S. W., Ingelsson, M., Westermark, P., and Westermark, G. T. (2015). In vivo seeding and cross-seeding of localized amyloidosis: a molecular link between type 2 diabetes and Alzheimer disease. Am. J. Pathol. 185, 834-846. doi: 10.1016/j.ajpath.2014.11.016

Owen, C. G., Jarrar, Z., Wormald, R., Cook, D. G., Fletcher, A. E., and Rudnicka, A. R. (2012). The estimated prevalence and incidence of late stage age related macular degeneration in the UK. Br. J. Ophthalmol. 96, 752-756. doi: 10.1136/bjophthalmol-2011-301109

Palacios, N., Gao, X., McCullough, M. L., Jacobs, E. J., Patel, A. V., Mayo, T., et al. (2011). Obesity, diabetes and risk of Parkinson's disease. Mov. Disord. 26, 2253-2259. doi: 10.1002/mds.23855

Parcerisas, A., Rubio, S. E., Muhaisen, A., Gómez-Ramos, A., Pujadas, L., Puiggros, M., et al. (2014). Somatic signature of brain-specific single nucleotide variations in sporadic Alzheimer's disease. J. Alzheimers Dis. 42, 1357-1382. doi: 10.3233/JAD-140891
Paterson, R. W., Torres-Chae, C. C., Kuo, A. L., Ando, T., Nguyen, E. A., Wong, K., et al. (2012). Differential diagnosis of jakob-creutzfeldt disease. Arch. Neurol. 69, 1578-1582. doi: 10.1001/2013.jamaneurol.79

Peng, S., Glennert, J., and Westermark, P. (2005). Medin-amyloid: a recently characterized age-associated arterial amyloid form affects mainly arteries in the upper part of the body. Amyloid 12, 96-102. doi: 10.1080/135061205001 07006

Pisa, D., Alonso, R., Juarranz, A., Rábano, A., and Carrasco, L. (2015a). Direct visualization of fungal infection in brains from patients with Alzheimer's disease. J. Alzheimers Dis. 43, 613-624. doi: 10.3233/JAD141386

Pisa, D., Alonso, R., Rábano, A., Rodal, I., and Carrasco, L. (2015b). Different brain regions are infected with fungi in Alzheimer's disease. Sci. Rep. 5:15015. doi: 10. 1038/srep15015

Pocchiari, M., Puopolo, M., Croes, E. A., Budka, H., Gelpi, E., Collins, S., et al. (2004). Predictors of survival in sporadic creutzfeldt-jakob disease and other human transmissible spongiform encephalopathies. Brain 127, 2348-2359. doi: 10.1093/brain/awh249

Preston, A. (2005). Bordetella pertussis: the intersection of genomics and pathobiology. CMAJ 173, 55-62. doi: 10.1503/cmaj.050105

Preusser, M., Ströbel, T., Gelpi, E., Eiler, M., Broessner, G., Schmutzhard, E., et al. (2006). Alzheimer-type neuropathology in a 28 year old patient with iatrogenic Creutzfeldt-Jakob disease after dural grafting. J. Neurol. Neurosurg. Psychiatry 77, 413-416. doi: 10.1136/jnnp.2005.070805

Prusiner, S. B. (2013). Biology and genetics of prions causing neurodegeneration. Annu. Rev. Genet. 47, 601-623. doi: 10.1146/annurev-genet-110711155524

Prusiner, S. B., Woerman, A. L., Mordes, D. A., Watts, J. C., Rampersaud, R., Berry, D. B., et al. (2015). Evidence for $\alpha$-synuclein prions causing multiple system atrophy in humans with parkinsonism. Proc. Natl. Acad. Sci. U S A 112 , E5308-E5317. doi: 10.1073/pnas.1514475112

Puopolo, M., Ladogana, A., Vetrugno, V., and Pocchiari, M. (2011). Transmission of sporadic Creutzfeldt-Jakob disease by blood transfusion: risk factor or possible biases. Transfusion 51, 1556-1566. doi: 10.1111/j.1537-2995.2010. 03004.x

Savica, R., Grossardt, B. R., Bower, J. H., Boeve, B. F., Ahlskog, J. E., and Rocca, W. A. (2013). Incidence of dementia with Lewy bodies and Parkinson disease dementia. JAMA Neurol. 70, 1396-1402. doi: 10.1001/jamaneurol.2013. 3579

Schernhammer, E., Hansen, J., Rugbjerg, K., Wermuth, L., and Ritz, B. (2011). Diabetes and the risk of developing Parkinson's disease in Denmark. Diabetes Care 34, 1102-1108. doi: 10.2337/dc10-1333

Simon, K. C., Chen, H., Schwarzschild, M., and Ascherio, A. (2007). Hypertension, hypercholesterolemia, diabetes and risk of Parkinson disease. Neurology 69, 1688-1695. doi: 10.1212/01.wnl.0000271883.45010.8a

Soto, C., and Estrada, L. D. (2008). Protein misfolding and neurodegeneration. Arch. Neurol. 65, 184-189. doi: 10.1001/archneurol.2007.56

Steenland, K., MacNeil, J., Seals, R., and Levey, A. (2010). Factors affecting survival of patients with neurodegenerative disease. Neuroepidemiology 35, 28-35. doi: 10.1159/000306055

Stern, M. B., Lang, A., and Poewe, W. (2012). Toward a redefinition of Parkinson's disease. Mov. Disord. 27, 54-60. doi: 10.1002/mds.24051

Sun, Y., Chang, Y. H., Chen, H. F., Su, Y. H., Su, H. F., and Li, C. Y. (2012). Risk of Parkinson disease onset in patients with diabetes: a 9-year population-based cohort study with age and sex stratifications. Diabetes Care 35, 1047-1049. doi: $10.2337 / \mathrm{dc} 11-1511$

Sutherland, G. T., Siebert, G. A., Kril, J. J., and Mellick, G. D. (2011). Knowing me, knowing you: can a knowledge of risk factors for Alzheimer's disease prove useful in understanding the pathogenesis of Parkinson's disease? J. Alzheimers Dis. 25, 395-415. doi: 10.3233/JAD-2011110026

Villar-Piqué, A., and Ventura, S. (2012). Modeling amyloids in bacteria. Microb. Cell Fact. 11:166. doi: 10.1186/1475-2859-11-166

Wang, L. (2009). Towards revealing the structure of bacterial inclusion bodies. Prion 3, 139-145. doi: 10.4161/pri.3.3.9922

Warren, J. D., Rohrer, J. D., Schott, J. M., Fox, N. C., Hardy, J., and Rossor, M. N. (2013). Molecular nexopathies: a new paradigm of neurodegenerative disease. Trends Neurosci. 36, 561-569. doi: 10.1016/j.tins.2013. 06.007 
Weissmann, C., Enari, M., Klohn, P. C., Rossi, D., and Flechsig, E. (2002). Transmission of prions. Proc. Natl. Acad. Sci. U S A 99, 16378-16383. doi: 10. 1073/pnas. 172403799

Wermuth, L., Bech, S., Petersen, M. S., Joensen, P., Weihe, P., and Grandjean, P. (2008). Prevalence and incidence of Parkinson's disease in the faroe islands. Acta Neurol. Scand. 118, 126-131. doi: 10.1111/j.1600-0404.2007.00991.x

Wermuth, L., Pakkenberg, H., and Jeune, B. (2002). High age-adjusted prevalence of Parkinson's disease among inuits in greenland. Neurology 58, 1422-1425. doi: 10.1212/wnl.58.9.1422

Westermark, G. T., and Westermark, P. (2010). Prion-like aggregates: infectious agents in human disease. Trends Mol. Med. 16, 501-507. doi: 10.1016/j. molmed.2010.08.004

Will, R. G., Zeidler, M., Stewart, G. E., Macleod, M. A., Ironside, J. W., Cousens, S. N., et al. (2000). Diagnosis of new variant Creutzfeldt-Jakob disease. Ann. Neurol. 47, 575-582. doi: 10.1002/1531-8249(200005)47:5<575::AIDANA4 > 3.0.CO;2-W

Wilson, P. W., Myers, R. H., Larson, M. G., Ordovás, J. M., Wolf, P. A., and Schaefer, E. J. (1994). Apolipoprotein E alleles, dyslipidemia and coronary heart disease. The framingham offspring study. JAMA 272, 1666-1671. doi: 10. 1001/jama.1994.03520210050031

Wilson, R., Read, R., Thomas, M., Rutman, A., Harrison, K., Lund, V., et al. (1991). Effects of Bordetella pertussis infection on human respiratory epithelium in vivo and in vitro. Infect. Immun. 59, 337-345.
Zaragoza, C., Gómez-Guerrero, C., Martín-Ventura, J. L., Blanco-Colio, L., Lavin, B., Mallavia, B., et al. (2011). Animal models of cardiovascular diseases. J. Biomed. Biotechnol. 2011:497841. doi: 10.1155/2011/ 497841

Zende, P. D., Bankar, M. P., Kamble, P. S., and Momin, A. A. (2013). Apolipoprotein e gene polymorphism and its effect on plasma lipids in arteriosclerosis. J. Clin. Diagn. Res. 7, 2149-2152. doi: 10. 7860/JCDR/2013/6195.3455

Zhang, W., Huang, W., and Jing, F. (2013). Contribution of blood platelets to vascular pathology in Alzheimer's disease. J. Blood Med. 4, 141-147. doi: 10 2147/JBM.s45071

Conflict of Interest Statement: The authors declare that the research was conducted in the absence of any commercial or financial relationships that could be construed as a potential conflict of interest.

Copyright (C) 2016 de Pedro-Cuesta, Martínez-Martín, Rábano, Ruiz-Tovar, AlcaldeCabero and Calero. This is an open-access article distributed under the terms of the Creative Commons Attribution License (CC BY). The use, distribution and reproduction in other forums is permitted, provided the original author(s) or licensor are credited and that the original publication in this journal is cited, in accordance with accepted academic practice. No use, distribution or reproduction is permitted which does not comply with these terms. 